\title{
PRESENTACION
}

\section{COMUNIDADES INTELECTUALES, TRAMAS INTERNAS Y LÓGICAS DE LO NOVEDOSO EN LA SEGUNDA MITAD DEL SIGLO XX LATINOAMERICANO}

María Paula Pino Villar Emiliano Matías Campoy

El presente dossier reúne los trabajos del grupo de investigación que conforma el Proyecto Plurianual Diacronia de lo nuevo en las comunidades letradas latinoamericanas. Textos públicos y redes en la segunda mitad del siglo $\chi \chi{ }^{1}{ }^{1}$ Los artículos que aquí se presentan buscan abordar las formas de lo novedoso en distintas comunidades letradas latinoamericanas. Las líneas de indagación se plantean en torno a las nuevas formas en que se expresa la cultura, como también en la emergencia de nudos conceptuales diferentes a los que sostenía el status quo hasta ese momento en las comunidades letradas de Latinoamérica. Por otro lado, también interesan las nuevas sociabilidades, es decir, la trama interna que evidencia lazos hasta entonces impensables entre intelectuales, por ejemplo entre comunistas y peronistas. No obstante, también dentro de los grupos ideológicamente afines surgen sociabilidades entre actores con actividades disímiles, como por ejemplo, militancias en sindicatos, curas tercermundistas, periodistas e intelectuales. Por lo tanto, las líneas que rigen estas formas de lo nuevo serán estudiadas en torno a la emergencia de nodos conceptuales antes

${ }^{1}$ Financiado por el Consejo Nacional de Investigaciones Científicas y Técnicas (CONICET), se desarrolló en el período comprendido entre los años 2015 y 2017, bajo la dirección del Dr. Claudio Maíz y codirección del Dr. Alejandro Paredes, con participación del Dr. Pablo Ponza y otros miembros de la Universidad Nacional de Córdoba, Universidad Nacional de Cuyo y el Instituto de Ciencias Humanas, Sociales y Ambientales de CONICET Mendoza. 
inexistentes, nuevos modos de sociabilidad entre intelectuales y nuevos lenguajes o formas de expresión.

Entre los nodos conceptuales antes inexistentes, el trabajo de María Paula Pino Villar profundiza sobre el surgimiento de nuevos modos de concebir al espectador en las artes visuales, en la segunda mitad de los 60. En cuanto a los nuevos modos de sociabilidad, el trabajo de Alejandro Paredes plantea la creación de una red intelectual ecuménica-comunista, en torno a la revista brasileña Paz e Terra. Por su parte, Pablo Ponza focaliza en la importante red de prestigiosos colaboradores, nacionales e internacionales, que se nuclearon en torno de la revista Crisis, uno de los proyectos editoriales de mayor vigor de los que se desarrollaron durante la segunda mitad del siglo pasado en Argentina. En ese mismo sentido, Gabriel Montali, al analizar el proceso de radicalización ideológica de Eduardo Galeano hasta mediados de la década de 1970, aborda las redes que fueron determinando de algún modo la trayectoria estético-política del intelectual uruguayo. Dentro de la emergencia de nuevos lenguajes o formas de expresión, Ramiro Zó propone pensar la novedad del testimonio como subgénero literario en la primera época de la Revista Crisis. En tanto que el trabajo de Matías Campoy se centra en las reflexiones sobre la relación entre arte y realidad social del grupo Tarja y en la búsqueda de nuevos modos expresivos mediantes los que ese grupo proponía la superación del folklorismo y el regionalismo tradicional imperantes hasta principios de los años cincuenta en la región noroeste argentina.

Estas líneas de investigación se sitúan en coordenadas espaciotemporales determinantes: Latinoamérica en la segunda mitad del siglo XX. La elección del período temporal (1955-1987) en el que se encuadra la investigación que en su conjunto proponen cada uno de estos artículos no es un dato menor. El convulsionado período de mitad de los años cincuenta, los años setenta y promediando los ochenta, interpela a los intelectuales que desde las páginas de revistas culturales, periódicos y catálogos de exposiciones artísticas ensayaron diversas reacciones por medio de proyectos condicionados por los procesos políticos y sociales. Sin lugar a dudas, las diversas crisis que se experimentaron por aquellos años promovieron la emergencia de nuevas propuestas tanto en el plano estético como ideológico. Existen dos puntos de partida para pensar las condiciones en que los intelectuales de la segunda mitad del siglo XX están produciendo, en primer lugar las tensiones propias de la Guerra Fría, y en el caso argentino puntualmente, la aversión o adhesión a las 
políticas del peronismo. El golpe autodenominado Revolución Libertadora, que en 1955 derrocó al Presidente Juan Domingo Perón, fue acompañado por sectores conservadores, la izquierda liberal y la Iglesia católica. El derrocamiento de Perón impactó de tal forma en el campo cultural argentino que no pocos estudiosos de la literatura de ese país han recurrido a ese año, y puntualmente a ese acontecimiento, como el comienzo de un período denominado los sesenta, que se extiende hasta 1976. Como se señala en el artículo de Campoy, es precisamente a finales de 1955 que comienza a publicarse la revista Tarja conformada por un grupo de intelectuales antiperonistas que, desde la provincia de Jujuy, buscaron revitalizar la idea de literatura regional y promovieron la reflexión y la práctica de una literatura comprometida. Pero, además, desde 1955, y durante dieciocho años, la proscripción del peronismo movilizó en Argentina distintos tipos de resistencias sociales y culturales, que fueron adquiriendo formas variadas. De hecho, Ponza advierte en su trabajo la solidaridad de Crisis "con el largo ciclo de protestas sociales que en Argentina combatieron la creciente suspensión de las actividades políticas institucionalizadas, cuya basa central había sido la marginación forzada del peronismo durante 18 años por parte de las Fuerzas Armadas".

Asimismo, la Guerra Fría tuvo uno de los episodios más significativos en el ámbito latinoamericano con la Revolución cubana de 1959, momento en el que se instaló en el continente el conflicto entre el capitalismo norteamericano y el socialismo soviético. La izquierda revolucionaria se volvió una opción atractiva para la juventud, que adquiere en los sesenta cada vez más protagonismo. Los intelectuales se suman a los sectores radicalizados de trabajadores, estudiantes y curas tercermundistas y asumen un rol activo en los alzamientos vanguardistas de los setenta. Los sucesivos golpes militares que adhirieron a la doctrina de Seguridad Nacional impuesta por los Estados Unidos en la región, llevaron adelante una verdadera cacería de comunistas, socialistas, intelectuales, militantes y simpatizantes de izquierda. El encarcelamiento, persecución, tortura y asesinato de personas signa la producción cultural latinoamericana, de manera distintiva. Montali al indagar en los cruces entre la trayectoria vital de Galeano con su labor intelectual, profundiza en la relación entre la obra del escritor uruguayo y el proyecto editorial de la revista Crisis, lo que permite comprender cómo las trayectorias vitales impactan en los proyectos colectivos trazando vínculos entre personalidades de diversas procedencias que confluyen. 
En la misma dirección, los artículos de Paredes y Zó evidencian cómo la persecución política incide directamente sobre la actividad cultural del período. Zó presenta el caso del subgénero testimonial en la Revista Crisis, y la particular "conciencia genológica y discursiva de lo testimonial flexible", que termina "apropiándose de un crisol de discursos tendientes a dar cuenta de los sufrimientos de presos y víctimas de crímenes de Estado". Zó describe distintos textos publicados en Crisis, desde microtestimonios en torno a la tortura, poemas testimoniales, diarios de tortura, hasta cartas de reclusos a familiares o epístolas de familiares a prisioneros. De este variado conjunto, extrae conciencia genológica que los aúna: "que se escribe para soportar el dolor, para sobrevivir al encierro y a la tortura, para curar heridas". También el artículo de Paredes se relaciona de forma directa con la dictadura militar brasileña, diseñada a favor de una élite y en consonancia con los intereses estadounidenses en la región, en el marco de la Guerra Fría. En este contexto, Paredes describe la dinámica específica del cuasi-grupo conformado en torno a la figura de Waldo Cesar y la Revista Paz e Terra. Paredes aborda los paralelismos en las trayectorias de los autores que publicaron en la revista que "les permitió encontrarse en un espacio de debate en común y articularse en un cuasi-grupo que, debido al sabotaje de la represión estatal, no alcanzó a conformar un grupo o una red político-religiosa".

Dentro de lo que se mencionó anteriormente como nuevos modos de sociabilidad, los trabajos aquí reunidos se proponen analizar el desarrollo de redes intelectuales como puntos gestantes de una novedad dentro del campo intelectual latinoamericano. Es decir, cómo grupos de intelectuales que se vincularon consolidando una determinada constelación promovieron deliberadamente la incorporación de lo novedoso y cómo eso impactó en los discursos generados en el seno de esos grupos. Más precisamente, los artículos se ocupan de cómo se plasman ciertas propuestas innovadoras en las revistas culturales que se consolidaron como vehículo expresivo del pensamiento crítico y reflexivo de tales grupos. Así por ejemplo, Ponza analiza cómo el proyecto editorial de Crisis desde una perspectiva latinoamericana, anti-imperialista, nacional y popular intentó incorporar la figura del intelectual como sujeto clave en el proceso revolucionario a partir tanto de la revisión historiográfica como de las intervenciones públicas conforme a la noción ética del compromiso. Por su parte, la revista Tarja, estudiada por Campoy, impulsa la idea de literatura comprometida y la función social 
del arte en la región noroeste argentina, en parte, como respuesta a los "esclerosados modos productivos que habían abonado los prejuicios impuestos desde la capital a la literatura elaborada en las regiones interiores del país" pero también a las tendencias que ingresaban al país por el puerto y de las que se hacían eco los escritores de la región metropolitana.

Esto último se relaciona con otra de las líneas aquí trabajadas que recoge, precisamente, las ideas impulsoras de algún cambio y su manifestación o materialización en revistas culturales publicadas entre 1955 y 1976 en el Cono Sur, donde se debate la modernidad de los sesenta. Resulta interesante advertir el comportamiento de las comunidades letradas aquí abordadas frente a la ruptura que propone lo novedoso. Víctor Godgel, al ocuparse de las conmociones que provocó la irrupción de la modernidad durante la primera mitad del siglo XIX en América Latina, considera que la experiencia de lo nuevo puede ser analizada desde dos perspectivas distintas: "la de quienes creen en la ruptura y la de quienes se muestran escépticos" (Estas reacciones se advierten también, como lo demuestran los artículos compilados en este trabajo, en las discusiones que comienzan a gestarse hacia mediados de la década del cincuenta, que harán eclosión en los años sesenta pero cuyas repercusiones se prolongaron en las décadas siguientes. La disparidad de reacciones frente a la experiencia de lo nuevo puede darse tanto hacia el interior de los grupos híbridos que conforman las redes intelectuales estudiadas como en el posicionamiento de una comunidad letrada en un marcado contrapunto con otras comunidades. La valoración de esas posturas ha despertado el interés de algunos de los trabajos aquí reunidos. Es decir, cómo determinado grupo o, en su defecto, alguna personalidad destacada y, de algún modo, representativa de una comunidad letrada, se expresa en momentos críticos o de ruptura ante la experiencia de lo novedoso. Para este caso resulta ejemplar el trabajo de Montali sobre la figura de Eduardo Galeano, prestando especial atención al entramado que se va consolidando entre su trayectoria vital y su labor intelectual. Es precisamente en esos debates determinados por las circunstancias en las que se desarrollaron en los que se hace visible el dinamismo y los derroteros de algunas ideas que impactaron con fuerza en Latinoamérica.

\footnotetext{
${ }^{2}$ GODGEL, Víctor. Cuando lo nuevo conquistó América. Prensa moda y literatura en el siglo XIX. Buenos Aires: Siglo XXI, 2013: 18
} 
Como dejan en claro estas investigaciones, advertir ese dinamismo, intentando analizar las causas y consecuencias de las modulaciones, allana el camino para comprender los procesos que ocasionalmente fueron modelando las ideas que movieron a la praxis de determinados grupos en los distintos campos culturales en los que realizaron su labor. Para el análisis de las manifestaciones de esas diversas posturas, y los debates que éstas suscitaron, los autores de este dossier toman en consideración los textos públicos que esos grupos produjeron en los que se visualizan, aunque no siempre de manera explícita, los objetivos sobre los que se fundaron algunos proyectos intelectuales que consolidaron las relaciones entre los miembros y, de este modo, configuraron las redes intelectuales aquí estudiadas.

A la luz de lo dicho anteriormente, resulta necesario señalar que lo nuevo no se origina exclusivamente como la instalación de algo que no existía con anterioridad. Lo novedoso en ocasiones resulta de resignificaciones creativas de elementos culturales, políticos, históricos o sociales muchas veces como respuestas a los conflictos epocales o como provocación, como manifiesto contestatario y contrahegemónico. También puede ser el resultado de una experimentación formal que busca revitalizar el campo cultural, de advertir la carencia de modos expresivos válidos para transmitir ciertas ideas, o bien de modulaciones de lo anterior con el fin de parodiarlo, atenuarlo, enriquecerlo y un largo listado de otras intenciones. En este sentido podría pensarse en cómo ciertos elementos culturales marginales adquieren un lugar destacado en el campo cultural. Tal parece ser el caso del género testimonial, en la literatura y, en las artes visuales, la estrategia de inspirarse en la cultura popular y de masas para propiciar experiencias tendientes a unir arte y vida. Este deseo de borrar los límites entre el vanguardismo y la cultura popular se repite en varios de los artículos aquí reunidos.

Muchas de las redes intelectuales aquí estudiadas respondieron a pulsiones internacionales cuya incorporación se debe a complejos procesos de asimilación más que a la mera copia. Es precisamente en esa adecuación en donde se evidencia algunas veces el giro novedoso. $\mathrm{O}$ bien, en otras ocasiones, es un elemento foráneo el que se convierte en centro de debate. En cuanto a las dinámicas propias del campo cultural latinoamericano de los años 60 , no se debe pasar por alto el boom editorial que vivió el continente por aquellos años y la decisiva irrupción de los escritores latinoamericanos que comenzaron a ejercer públicamente su capacidad intelectual. Esto contribuyó a que las opiniones del escritor 
intelectual fueran recabadas para dar cuenta de diversos aspectos de la vida nacional o, incluso continental, hecho que lo posicionó en el centro de la escena, dándole una importante visibilidad pública. Esa mayor visibilidad alcanzada por algunos intelectuales contribuyó a la conformación de redes que fueron congregándose a la sombra de esas figuras tutelares que alumbraron proyectos de novedosas propuestas e inaudita proyección y repercusión. De ahí la necesidad de advertir esas tramas o conexiones no siempre declaradas o evidentes pues esto permite focalizar no en los resultados sino en los complejos procesos de gestación y conformación de lo novedoso. La crítica especializada también ha señalado como uno de los factores que allanaron el terreno para el boom editorial el auge de nuevos públicos lectores que comenzaron a interesarse en problemáticas de la época. La incorporación de estos nuevos públicos fue uno de los objetivos de la revista Crisis, como bien lo advierten Montali, Ponza y Zó en sus artículos. Pero también fue una preocupación que agitaba el campo artístico visual del período, como lo describe Pino Villar en su abordaje sobre la irrupción del Pop art y el cinetismo en Argentina.

Los trabajos aquí reunidos buscan revisitar no el hecho consumado y aparente sino analizar los mecanismos -o, incluso, los componentes y sus aspectos relacionales que conforman esos mecanismos- que lo fueron modelando. Mecanismos en los que a veces destaca la acción de un solo individuo, es decir, el producto consumado por una trayectoria vital, pero que en ocasiones es el resultado de un proyecto colectivo, de la suma de trayectorias que confluyen en conjuntos híbridos que con frecuencia superan los marcos nacionales, las fronteras o límites disciplinarios. Estos agrupamientos han sido integrados mayoritariamente por artistas, escritores, militantes y activistas con predilección por la escritura en un sentido amplio. Hay ciertas personalidades que activan y mueven, organizan y reúnen las piezas de una red; hay otras que se construyen, que sobresalen o que su interés simplemente se explican por su participación en una determinada red o comunidad letrada. De todas formas, el pensar a partir de la idea de redes permite descubrir que los gestos solitarios muchas veces son en realidad gestos solidarios que responden a tramas invisibles. 